\title{
Ixora chinensis Lamk. Flower Extract Health Drink
}

\author{
Buavaroon Srichaikul* as a corresponding authorFaculty of Public Health, Nutritional \\ Department, Mahasarakham University, Thailand 44150.
}

\section{E-mail: Buacanada@gmail.com}

\begin{abstract}
Objective: Health Drinks currently are one of the most popular demand of consumption drink product in Thailand globally. We found that many anti-aging health drink products were developed under sub- standard and did not meet the Thai FDA requirements in the area of toxicities and bioactivities. This study aimed to evaluate the anti oxidant activities of different methods of extraction and maceration of solvents, bioactivity quantities , toxicity, active ingredients of Ixora chinensis Lamk., flower extract health drink .
\end{abstract}

Methods: We studied different methods of extraction between Ultrasonication and maceration with $40 \%$ and $50 \%$ ethyl alcohol to compare the obtained amount of antioxidants in Ixora chinensis Lamk., flower extract health drink. We compared yields with different period of time and also analysis of antioxidant activities with DPPH, FRAP and ABTS methods, total phenolic compound, active ingredients by HPLC and acute toxicity analysis in white wistar rats by oral administrating of Ixora chinensis Lamk., flower extract for after $24 \mathrm{~h}$ and $14 \mathrm{~d}$.

Result: The study revealed no signals of acute toxicity in Ixora chinensis Lamk., flower extract which consisted of high contents of rutin, caffeoylquinic acid, chlorogenic acid, quercetin, iso-quercetin and cathechin using HPLC. Mean of gallic acid and catechin contents $(\mu \mathrm{g} / \mathrm{mg}$ extract) were 13.62 and 6.08. The result of the highest total flavonoids ( $\mu$ g quercetin/mg sample extract) with macerating in $50 \%$ ethanol at $4^{\text {th }}$ day was 0.6 .

Conclusion: We suggested that the result of active ingredients from the flower extract showed no statistical significant difference between macerating with water, $40 \%$ ethanol, $50 \%$ of ethanol and using ultrasonication method. Ixora chinensis Lamk. flower extract health drink was safe and contained high anti oxidant active ingredients. Therefore it would be suitable for developing anti aging health drink for the future .

Keyword: Ultrasonication Extraction, Phenolic content, Flavonoids, Acute Toxicity, Hematological value, Wistar White Rats

\section{Introduction}

Ixora chinensis Lamk usually grew in the southern area of Thailand which commonly was named as "Dauk Chem “. It was classified as jungle geranium, flame of the woods, and jungle flame which was in a Rubiaceae family. The plant was often grown as an annual in temperate and cooler climates which bloomed all year especially in rainy season during March to June.[8]. The plants were favorable to be slightly in the sun or shady. Ixora 
chinensis Lamk had a delicacy, various colors which could be extracted and developed as health drink. The flowers could also be cooked in some Thai cuisines and the leaves had a great deal of medicinal values in phytochemical studies. The plant contained important phytochemicals such as lupeol, ursolic acid, oleanolic acid, sitosterol, rutin, lecocyanadin, anthocyanins, proanthocyanidins, glycosides of kaempferol and quercetin[14]. Pharmacological studies suggest that the plant possessed antioxidative, antibacterial[1][5,6], gastroprotective, hepatoprotective, antidiarrheal, antinociceptive, antimutagenic, antineoplastic and chemo preventive effects, thus lending scientific support to the plant's ethnomedicinal uses.[16][17] Anti aging drink which consisted of 1-3 kg with 1.5 L of water and 1liter of Ixora chinensis Lamk flower extract extracted from 100-300 g of Ixora chinensis Lamk flower which could yield $0.4 \mathrm{~L}$ of flower extract. Both parts were adjusted to $\mathrm{PH}$ at $4,70{ }^{0} \mathrm{C}$ with honey syrup qs. add to 5L [21]. The drink could decrease constipation[15]. Ixora chinensis Lamk. inhibited formation of lipid peroxide and protein in oxidation and aldose reductase which could inhibit severity of diabetic disease . Antioxidant activity of Ixora chinensis Lamk could decrease the stress oxidation from free radical scavenging enzymes and lipid peroxidation by inducing lead acetate in rat .The result was found that Ixora chinensis Lamk. can inhibit the lead-induced oxidative stress. Methanol, acetone, $(50 \%, 90 \%$ and $100 \%)$ were used for the extraction of phenolic volatile[12].The analysis of highest total phenolic extraction was at the amount of $1431 \mathrm{mg} / \mathrm{QE} 100 \mathrm{~g}$. using $50 \%$ acetone as extraction solvent. $[8,9,15,16]$. This study was aimed at analyzing the active ingredients of Ixora chinensis Lamk. flower extracts using HPLC[11] such as antioxidant and total phenolic compound[12], flavonoid, and also investigated the comparison of anti oxidant activities by DPPH, FRAP and ABTS method using different kinds of extraction solvents such as water, $40 \%, 50 \%$ ethanol and with ultrasonication method[20]. Ultrasonication method was the method for extraction using high frequency ultrasonic sound for extraction purpose with small amount of time without using high temperature [20]. The study also investigated the analysis of acute toxicity of Ixora chinensis Lamk flower extract in white vista rats as experimental group and control group [13].

\section{Materials and Methods}

\section{Sample Selection}

The complete and healthy petal shape of Ixora flowers were selected as a samples Ixora species from Ixora chinensis Lamk farm in Samut Songkram province, central south of Thailand during October, 2014. The samples were dried in air at normal room temperature for $7 \mathrm{~d}$ and also dried in hot air oven at $50 \mathrm{C}$ for $24 \mathrm{~h}$ until completely dried. The dried sample of Ixora chinensis Lamk flowers were kept in closed container at room temperature for preparing in next step of extractions.[14,13]

\section{Extraction of Samples}

\section{Extraction with $40 \%$ ethanol, $50 \%$ ethanol by Ultrasonication Method}

Ultrasonication Method was the method for extraction using high frequency ultrasonic sound for extraction purpose with small amount of time without using high temperature 
[20].The sample was extracted with ultrasonication extraction for30 min .Solvents used were $40 \%$ ethanol, $50 \%$ ethanol. The proportion of samples extraction solvent was $1: 50 \mathrm{w} / \mathrm{v}$ [2]. Then the solution was filtered using filter paper no.0. The filtered solution was then evaporated using evaporator at $50 \mathrm{C}$ and was transferred to be proceeded in Freeze Dried equipment for drying. The data of fresh and dried weight of yields were recorded before and after freeze dried method. The freeze dried coarse samples were kept in closed container and was waiting for further analyzing steps.[3,4,20,21]

\section{Extraction with water by Ultrasonication Method.}

The sample was extracted with ultrasonication extraction for30 minutes Solvents used were purified water. The proportion of samples extraction : solvent was 1: $50 \mathrm{w} / \mathrm{v}$.Then the solution was filtered using filter paper no.0. The data of fresh and dried weight of yields were recorded before and after maceration with water[20, 21].

\section{Extraction with ethanol maceration for $7 \mathrm{~d}$}

The samples of Ixora chinensis Lamk flower was macerated with 50\% ethanol and $40 \%$ ethanol for $7 \mathrm{~d}$. The coarse extracted powder were collected daily for $7 \mathrm{~d}$ and The proportion of samples extraction : solvent was 1: $50 \mathrm{w} / \mathrm{v}$.Then the solution was filtered using filter paper no.0. The data of fresh and dried weight of yields were recorded before and after maceration with water then samples were kept in a closed container and was waiting for further analyzing steps.[20,21]

\section{Bioactivity Analysis}

\section{Total Phenolic content Analysis}

The standardized gallic acid at concentration of $12.5-1,000 \mu \mathrm{g} / \mathrm{ml}$ in $80 \%$ ethanol and also the sample of Ixora chinensis Lamk flower extract at concentration of $1 \mathrm{mg} / \mathrm{ml}$ in $80 \%$ ethanol were prepared on 3 replications. The analysis was carried in 96-well micro titerplate added with $25 \mathrm{ml}$ of samples and standardized solution of $125 \mu \mathrm{g} / 1$ Follin Ciocalteu reagent was added and rested for $5 \mathrm{~min}$ at room temperature, then we added $75 \mathrm{~g} / \mathrm{l} \mathrm{Na} 2 \mathrm{Co} 3$ for $100 \mu \mathrm{g}$ and distilled water qs. to $300 \mu \mathrm{g}$ and the solution was rested at room temperature for 2 hours until completing the reaction. The final solution was brought to be measured the concentration and the absorbance with spectrometer(micro plate) at 760 nanometer wavelength. Graph were plotted between the relationship of concentration of samples and the absorbance of light in order to calculate the result of total phenolic content related to gallic acid equivalent ( $\mu \mathrm{g}$ gallic acid /mg extract ) [5,6,18].

\section{Flavonoid content analysis}

Standardized Quercetin at conc. of 12.5 -1000 microgram / $\mathrm{ml}$ in $80 \%$ ethanol was prepared. Samples of Ixora chinensis Lamk flower extract was prepared at concentration of $1 \mathrm{mg} / \mathrm{ml}$ in $80 \%$ ethanol in 3 replications. All were tested in 96 well plate by adding 25 micro liter of ample and 75 micro liter of $95 \%$ ethanol. Then 5 micro liter of $10 \% \mathrm{AlCl} 3,5$ micro liter of $1 \mathrm{~mol} \mathrm{K3COOH}$ were added to the solution and qs. added to 140 micro liter 
with distilled water. The solution was rested at room temperature for 30 minutes until completing the reaction. The final solution was brought to be measured the concentration and the absorbance with spectrometer(micro plate) at 415 nanometer wavelength. Graph was plotted and interpreted in linear equation to identify the relationship between standardized quercetin concentration and the concentration of sample related to the absorbance light. The absorbance value from given sample was interpreted and changed to standard graph of flavonoid content which was equivalent to quercetin (microg quercetin /mg extract) $[1,6,9,10]$

\section{Analysis of anti oxidant activity by DPPH method}

Ixora chinensis Lamk Jack R.M.Smith Flower Extract were prepared in 5 concentrations (15-500 microg $/ \mathrm{ml})$ of ethanol in test tube. DPPH was prepared in 60 microgram /liter of ethanol. The 750 micro liter of flower extract was prepared in 750 micro liter of DPPH and were kept at room temperature for complete reaction for $20 \mathrm{~min}$. Then the solution was brought to be measured with Spectrometer using UV light at $517 \mathrm{~nm}$ wavelength . The \% radical scavenging was calculated with the formula below :

$\%$ radical scavenging $=($ A control $-\mathrm{A}$ sample $) \times 100$
(A control)
A control group was using an absorbance value of UV light
A sample group was using an absorbance value of UV light
The graph was plotted between concentration of Ixora chinensis Lamk flower extract and \% radical scavenging in order to calculate EC 50 value. All data were collected and recorded in order to calculate $\%$ of antioxidant and standard deviation of percent of radical scavenging. The results showed the comparison of EC 50 of samples and antioxidant standard substance of ascorbic acid.[2,5,8]

\section{Analysis of antioxidant activity by FRAP assay method}

Ixora chinensis Lamk flower extract was prepared at concentration of $1 \mathrm{mg} / \mathrm{ml}$.The FRAP reagent was also prepared which consisted of acetate buffer : $\operatorname{TPTZ}(2,4,6$-tripyridyl striazine) and ferric chloride. The proportion of the 3 reagents was 30:1:1. Then 100 micro liter of Ixora chinensis Lamk flower extract was mixed with 3,000 micro liter of FRAP reagent in the test tube in order to complete reaction. The mixture was brought to measure the absorbance at $593 \mathrm{~nm}$. wavelength in 10 minutes with spectrometer and compared the standard curve of the graph of Feso4 in order to evaluate the $\mathrm{Fe} 2$ (Fe equivalent ) for 6 replications. Feso4 solution were prepared at 0.1, 0.25,0.5,1.0, 2.5 and 5.0 millimol . Each test tube contained 100 micro liters reacted with 3,000 micro liters FRAP reagent. The solution was brought to measure the absorbance value at $593 \mathrm{~nm}$ wavelength of UV light in order to build the standard graph and showed the relationship with concentration of Feso4. 
Data collection was recorded and calculated the comparison of Fe 2 equivalent of samples and antioxidant activity reagent. $[2,5,7]$

\section{Analysis of antioxidant activity by ABTS assay method}

The standard Trelox solution was prepared at concentration of $12.5-1000 \mu \mathrm{g} / \mathrm{ml}$ in $80 \%$ ethanol and samples of Ixora chinensis Lamk flower extract was also prepared at concentration of $1 \mathrm{mg} / \mathrm{ml}$ in $80 \%$ ethanol with 3 replication. The ABTS solution was prepared by mixing $7 \mathrm{mM}$ ABTS with 2.45 milli mol potassium per sulfate of the same ratio in the distilled water and the solution was kept in dark at room temperature for 6 hours and was dissolved with $\mathrm{CH} 3 \mathrm{OH}$ until obtaining the absorbance at 1.00 with $734 \mathrm{~nm}$. of UV wavelength .[2][5][7][10]. The test was carried in the 96 well plate with standard sample at 150 micro liter. 150 micro liter of ABTS solution was added and kept in room temperature for 6 min for completion of reaction. The solution was brought to measure the concentration of Ixora chinensis Lamk flower extract sample against the absorbance with Spectrometer (micro plate reader) at $734 \mathrm{~nm}$. wave length. The absorbance relating to Ixora chinensis Lamk flower extract and standard graph to convert and to calculate equivalent value to Trolox solution. ( Trolox equivalent ) or(microgram Trolox /mg extract) [17,19].

\section{Statistical analysis}

Descriptive statistic used were mean, standard error of means(SEM). Inferential statistic used were one-way analysis of variance, ANOVA )and testing the homogeneity of variance using 1 -sample K-S and testing of normal distribution using RUN -test.We found that the result of population and sample were normal distribution therefore the sample was capable to further test for hypothesis evaluation. The statistic of testing the hypothesis of antioxidant activity between standard solution and sample solutions extracted from different kind of solvent solutions was one- way ANOVA. The result was found that there was statistical significant different at p-value 0.05. Therefore we have used SPSS version 15 to evaluate the average mean scores in each pair of sample solutions test using Scheffe "s test .[18]

\section{Acute toxicity analysis of Ixora chinensis Lamk flower extract}

\section{Preparation of raw material of Ixora chinensis Lamk flowers}

Samples of Ixora chinensis Lamk flower extract flowers were collected from Aumphawa farm, Samutsongkram, Thailand. We selected the healthy petals for running the experiment. The Ixora chinensis Lamk flower samples were cleaned with purified water and dried in hot air oven at $50 \mathrm{C}$.Dried flowers were blended to powder form.[13] The powder of dried Ixora chinensis Lamk flowers were macerated in $50 \%$ ethanol using the proportion of 1:50. They were extracted by ultrasonication method for $30 \mathrm{~min}$ and was filtered with thin white cloth and filtered second time with filtered paper. The filtered portion was brought to be evaporated using rotary evaporator for drying the filtered portion free from ethanol 
solvent and was brought to proceed freeze drying process. The freeze dried powder was given to white vista rat orally by mixing with $0.5 \%$ tween $80 \%$ solvent in order to test acute toxicity further.

\section{Preparation of experimental white vista rats}

Female and male albino vista rats were used in acute toxicity analysis of Ixora chinensis Lamk flower extracts with 200-250 g.body weight. Before the experiment,we have to control room temperature for keeping and feeding the experimental rats at $25+$ and $-2 \mathrm{C}$ ,relative humidity at 40-60\% and exposed them with the light $12 \mathrm{~h}$ daily and fed them with food and water through the experiment.[13].

\section{Experimental analysis in acute toxicity}

We used a randomized control trial in this study with Fixed Effect model using 2 factors which were normal control albino vista rats with $0.5 \%$ Tween 80 as a control group and in $2000 \mathrm{mg}$ of orally induced Ixora chinensis Lamk flower extracts per $1 \mathrm{~kg}$ of albino vista rats using orogastric tube through their mouths as an experimental group. All wistar white rats had 200-250 g. body weight. The volume used was $1 \mathrm{ml}$ of Ixora chinensis Lamk flower extracts to each experimental rat groups and $1 \mathrm{ml}$ of $0.5 \%$ Tween 80 to each control rat groups. [13].

\section{Data observational symptoms of rats for acute toxicity analysis}

We observed and recorded abnormality symptoms of experimental rats after $24 \mathrm{~h}$ and after $14 \mathrm{~d}, 2$ times daily observations continuously such as breathing, ingestion, excretion, defecation, motility, suture, disorientation, anorexia, vomiting ,the changes in weight including the records the numbers of mortality rats. At the end of experiment we had proceeded the cervical dislocation of all rats and used their blood samples from cardiac injection and brought them for hematological analysis. The statistical used were mean, percentage, standard deviation, standard error mean using SPSS.

\section{Total Phenolic contents of Ixora chinensis Lamk flower extract analysis}

We followed the highest antioxidant analysis which composed the compounds of Acetonitrite (A), $0.01 \%$ trifluoroacetic acid (B), The flow rate analysis at $1.0 \mathrm{ml} / \mathrm{min}$ under specific gradients $[2,19]$ as follows :

Time (min ) Ratio of solvents(A\%)

0-5 20-25

$5-10 \quad 25$

$10-12$ 
We have injected the samples of Ixora chinensis Lamk., Ixora spp flower extracts into 10 micro liter and compared with the standard substance of $(1=$ gallic acid, $2=$ catechin, $3=$ chlorogenic acid, $4=$ rutin, $5=$ ferulic acid $6=$ quercetin )at concentration of $50-500$ microgram $/ \mathrm{ml}$, at $280 \mathrm{~nm}$, wavelength of UV light and calculated Total Phenolic contents in Ixora chinensis Lamk flower extracts.

\section{Results}

Fresh weight / Dried weight of Ixora chinensis Lamk., flowers. Data was collected after hot air processing method .

Table .1 showed \% yield of fresh weight and dried weight of Ixora chinensis Lamk., flowers .

$\begin{array}{cccc}\text { Plant } & \text { Fresh weight (g.) } & \text { Dry weight (g.) } & \text { \% Yield } \\ \text { Ixora chinensis Lamk } & 20.05 & 3.56 & 17.76\end{array}$

Bioactivity analysis results of Ixora chinensis Lamk flower extracts

The result of bioactivity analysis using DPPH ( shown in table. 2) , ABTS (shown in table . 3 ), FRAP (shown in table .4) antioxidant activity analysis, Total Phenolic content (shown in table . 5), Total Flavonoid content (shown in table .6) and the results also were compared with the ultrasonication extraction using the water maceration up to $7 \mathrm{~d}$ maceration with50 \% and $40 \%$ ethanol. All results of active ingredients from the flower extract showed no statistical significant difference between macerating with water, $40 \%$ ethanol , 50\% of ethanol and using ultrasonication method $[3,5,6]$.

Table .2 Showed antioxidant activity of Ixora chinensis Lamk flower extracts with Vitamin C by DPPH method

\begin{tabular}{|c|c|c|c|}
\hline code & plant & Extract method & Mean \pm sd \\
\hline 1 & \multirow{9}{*}{$\begin{array}{l}\text { Ixora } \\
\text { chinensis } \\
\text { Lamk }\end{array}$} & Sonicate $50 \% \mathrm{EtOH}$ & $0.04 \pm 0.00$ \\
\hline 2 & & Sonicate $40 \% \mathrm{EtOH}$ & $0.23 \pm 0.07$ \\
\hline 3 & & Macer water & $0.25 \pm 0.01$ \\
\hline 4 & & Macer $50 \%$ EtOH d2 & $0.05 \pm 0.00$ \\
\hline 5 & & Macer 50\% EtOH d4 & $0.03 \pm 0.00$ \\
\hline 6 & & Macer $40 \%$ EtOH d4 & $0.06 \pm 0.02$ \\
\hline 7 & & Macer $40 \%$ EtOH d5 & $0.06 \pm 0.02$ \\
\hline 8 & & Macer 50\% EtOH d6 & $0.03 \pm 0.01$ \\
\hline 9 & & Macer $40 \%$ EtOH d6 & $0.03 \pm 0.00$ \\
\hline
\end{tabular}


Table..3 Result of antioxidant activity using ABTS (IC $50, \mu \mathrm{g} / \mathrm{ml})$

\begin{tabular}{|c|c|c|c|}
\hline Code & plant & Extract method & mean \pm sd \\
\hline 1 & \multirow{9}{*}{$\begin{array}{l}\text { Ixora } \\
\text { chinensis } \\
\text { Lamk }\end{array}$} & Sonicate $50 \% \mathrm{EtOH}$ & $0.29 \pm 0.00$ \\
\hline 2 & & Sonicate $40 \% \mathrm{EtOH}$ & $0.643 \pm 0.33$ \\
\hline 3 & & Macer water & $0.46 \pm 0.01$ \\
\hline 4 & & Macer $50 \%$ EtOH d2 & $0.36 \pm 0.00$ \\
\hline 5 & & Macer $40 \%$ EtOH d2 & $0.38 \pm 0.00$ \\
\hline 6 & & Macer $50 \%$ EtOH d3 & $0.24 \pm 0.01$ \\
\hline 7 & & Macer $40 \%$ EtOH d5 & $0.40 \pm 0.01$ \\
\hline 8 & & Macer $40 \%$ EtOH d6 & $0.24 \pm 0.01$ \\
\hline 9 & & Macer $40 \%$ EtOH d7 & $0.36 \pm 0.00$ \\
\hline
\end{tabular}

Table. 4 Result of antioxidant analysis using FRAP ( $\mu$ g Fe equivalent/g sample)

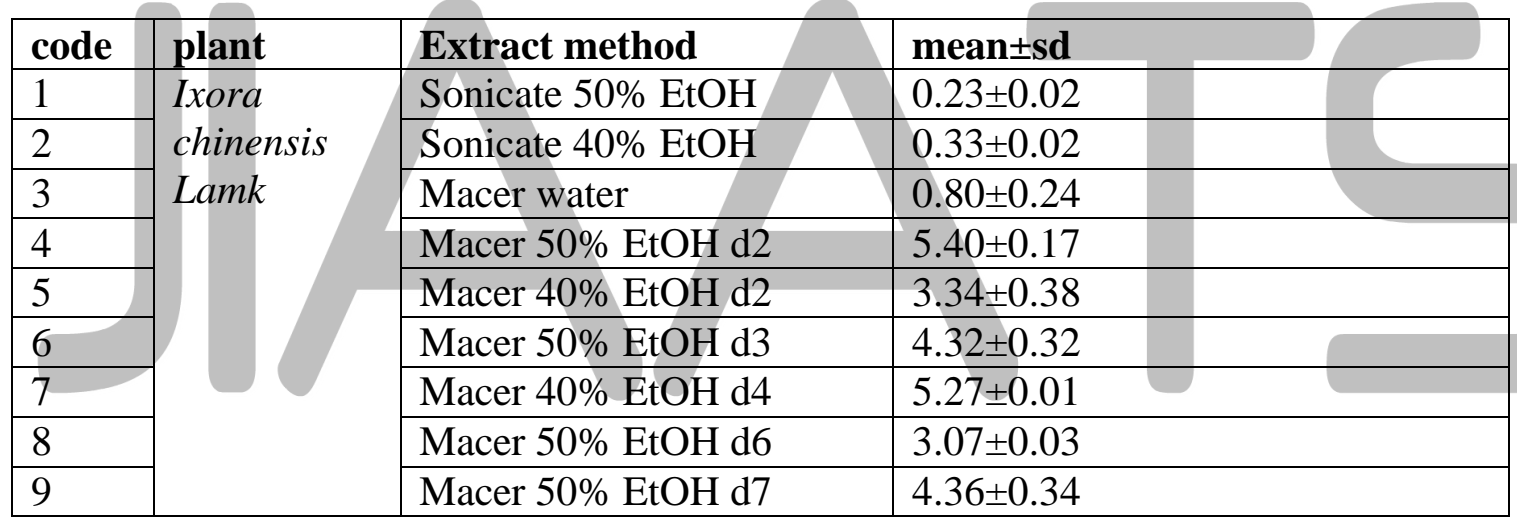

Table.5 Result in Total Phenolic analysis ( $\mu$ g Gallic acid equivalent/g sample)

\begin{tabular}{|c|c|c|c|}
\hline code & plant & Extract method & mean \pm sd \\
\hline 1 & \multirow{7}{*}{$\begin{array}{l}\text { Ixora } \\
\text { chinensis } \\
\text { Lamk }\end{array}$} & Sonicate $50 \% \mathrm{EtOH}$ & $0.18 \pm 0.01$ \\
\hline 2 & & Sonicate $40 \% \mathrm{EtOH}$ & $0.23 \pm 0.01$ \\
\hline 3 & & Macer water & $0.09 \pm 0.01$ \\
\hline 4 & & Macer 50\% EtOH d1 & $0.30 \pm 0.00$ \\
\hline 5 & & Macer $50 \%$ EtOH d3 & $0.30 \pm 0.00$ \\
\hline 6 & & Macer $50 \%$ EtOH d4 & $0.30 \pm 0.00$ \\
\hline 7 & & Macer $50 \%$ EtOH d5 & $0.30 \pm 0.00$ \\
\hline
\end{tabular}




\begin{tabular}{|l|l|l|l|}
\hline 8 & & Macer 50\% EtOH d6 & $0.29 \pm 0.00$ \\
\cline { 3 - 4 } 9 & Macer 50\% EtOH d7 & $0.30 \pm 0.00$ \\
\hline
\end{tabular}

Table.6. Showed the contents of Total flavonoid ( $\mu$ g quercetin/mg sample)

\begin{tabular}{|c|c|c|c|}
\hline code & plant & Extract method & Mean \pm sd \\
\hline 1 & \multirow{9}{*}{$\begin{array}{l}\text { Ixora } \\
\text { chinensis } \\
\text { Lamk }\end{array}$} & Sonicate $50 \% \mathrm{EtOH}$ & $0.30 \pm 0.00$ \\
\hline 2 & & Sonicate $40 \% \mathrm{EtOH}$ & $0.34 \pm 0.25$ \\
\hline 3 & & Macer water & $0.09 \pm 0.00$ \\
\hline 4 & & Macer $50 \%$ EtOH d3 & $0.31 \pm 0.25$ \\
\hline 5 & & Macer $40 \%$ EtOH d3 & $0.33 \pm 0.17$ \\
\hline 6 & & Macer $50 \%$ EtOH d5 & $0.34 \pm 0.13$ \\
\hline 7 & & Macer $40 \%$ EtOH d5 & $0.19 \pm 0.16$ \\
\hline 8 & & Macer $50 \%$ EtOH d6 & $0.24 \pm 0.06$ \\
\hline 9 & & Macer $50 \%$ EtOH d7 & $0.39 \pm 0.33$ \\
\hline
\end{tabular}

\section{Result in Acute toxicity analysis of Ixora chinensis Lamk flower extract}

We observed and recorded result in Acute toxicity analysis of Ixora chinensis Lamk flower extract which showed no abnormality symptoms in experimental rats after $24 \mathrm{~h}$ and after $14 \mathrm{~d}$ with 2 times daily observations continuously such as breathing, ingestion, excretion, defecation, motility, suture, disorientation, anorexia, vomiting ,the changes in weight including the records the numbers of mortality rats. At the end of experiment we proceeded the cervical dislocation of all rats and used their blood samples from cardiac ejections and brought them for hematological analysis such as Blood Glucose, BUN, Creatinine, Uric acid, Cholesterol, Triglyceride, LDL, HDL, total protein , albumin , globulin, total bilirubin, AST, ALT including the comparison of internal organ weights of control and experimental group of albino vista rats such as liver, kidney, heart and lung . The statistical used were mean, percentage, standard deviation, standard error mean using SPSS[13].

Table7.Showed the result of haematological values in wistar rats by Ixora chinensis Lamk flower extract $(2,000 \mathrm{mg} / \mathrm{kg}$ body weight. $)$

\begin{tabular}{lll}
\hline parameters & Control group & Ixora chinensis Lamk. \\
\hline Glucose $(\mathrm{mg} / \mathrm{dl})$ & $146.60 \pm 8.15^{\mathrm{a}}$ & $157.33 \pm 9.32^{\mathrm{a}}$ \\
$\mathrm{BUN}(\mathrm{mg} / \mathrm{dl})$ & $26.48 \pm 1.58^{\mathrm{a}}$ & $27.75 \pm 1.36^{\mathrm{a}}$ \\
\hline
\end{tabular}




\begin{tabular}{lll}
\hline Creatinine $(\mathrm{mg} / \mathrm{dl})$ & $0.84 \pm 0.02^{\mathrm{a}}$ & $0.95 \pm 0.02^{\mathrm{a}}$ \\
Uric $(\mathrm{mg} / \mathrm{dl})$ & $3.72 \pm 0.28^{\mathrm{a}}$ & $3.36 \pm 0.23^{\mathrm{a}}$ \\
Cholesterol $(\mathrm{mg} / \mathrm{dl})$ & $78.00 \pm 5.95^{\mathrm{a}}$ & $73.16 \pm 5.38^{\mathrm{a}}$ \\
& & \\
& & \\
& & \\
$\mathrm{TG}(\mathrm{mg} / \mathrm{dl})$ & $123.60 \pm 13.41^{\mathrm{a}}$ & $117.33 \pm 15.95^{\mathrm{a}}$ \\
$\mathrm{HDL}(\mathrm{mg} / \mathrm{dl})$ & $16.60 \pm 1.12^{\mathrm{a}}$ & $15.83 \pm 1.04^{\mathrm{a}}$
\end{tabular}

Table.7 Showed the result of haematological values in wistar rats by Ixora chinensis Lamk flower extract $(2,000 \mathrm{mg} / \mathrm{kg}$ body weight.) continued

\begin{tabular}{lll}
\hline Parameters & Control group & $\begin{array}{l}\text { Ixora chinensis Lamk flower } \\
\text { extract }\end{array}$ \\
\hline LDL(mg/dl) & $38.00 \pm 5.31^{\mathrm{a}}$ & $37.00 \pm 3.17^{\mathrm{a}}$ \\
Total protein(mg/dl) & $6.06 \pm 0.12^{\mathrm{a}}$ & $5.76 \pm 0.05^{\mathrm{a}}$ \\
& $3.86 \pm 0.06^{\mathrm{a}}$ & $3.75 \pm 0.02^{\mathrm{a}}$ \\
Albumin(g/dl) & $2.20 \pm 0.07^{\mathrm{a}}$ & $2.01 \pm 0.04^{\mathrm{a}}$ \\
Globulin(g/dl) & \\
Total & $0.30 \pm 0.03^{\mathrm{a}}$ & $0.26 \pm 0.03^{\mathrm{a}}$ \\
(mg/dl) & & \\
AST(U/L) & $78.60 \pm 2.60^{\mathrm{a}}$ & $77.50 \pm 3.14^{\mathrm{a}}$ \\
& & \\
ALT(U/L) & $29.20 \pm 0.96^{\mathrm{a}}$ & $28.00 \pm 1.61^{\mathrm{a}}$ \\
\hline
\end{tabular}

Table.8 showed the result of internal organ weight (g.) of wistar rats by Ixora chinensis Lamk flower extract $(2,000 \mathrm{mg} / \mathrm{kg}$ body weight. $)$

\begin{tabular}{ll}
\hline organ Control group & $\begin{array}{l}\text { Ixora chinensis Lamk flower } \\
\text { extract }\end{array}$ \\
\hline
\end{tabular}




\begin{tabular}{lll}
\hline Liver & $4.84 \pm 0.31^{\mathrm{a}}$ & $5.13 \pm 0.60^{\mathrm{a}}$ \\
Kidneys & $0.76 \pm 0.04^{\mathrm{a}}$ & $0.89 \pm 0.06^{\mathrm{a}}$ \\
Heart & $0.44 \pm 0.02^{\mathrm{a}}$ & $0.42 \pm 0.02^{\mathrm{a}}$ \\
Lungs & $0.58 \pm 0.04^{\mathrm{a}}$ & $0.71 \pm 0.09^{\mathrm{a}}$
\end{tabular}

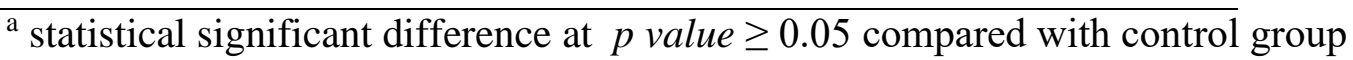

\section{Result of active ingredients from HPLC analysis}

The active ingredients were investigated such as Gallic acid, Catechin, Ferulic acid and Rutin (as shown in table no. 9 ) [12)]. The analysis of total phenolic contents were selected from highest oxidant activity from the extraction in order to analyze the compositions $[11,12]$ which composed of Acetonitrile (A) and $0.01 \%$ trifluoroacetic acid (B) ,rate of flow was calculated at $1.0 \mathrm{ml} / \mathrm{min}$ under gradient conditions as follows:

\begin{tabular}{ll}
\hline Time (min) & Ratio of solvent A (\%) \\
\hline $0-5$ & $20-25$ \\
$5-10$ & 25 \\
$10-12$ & $25-30$ \\
$12-15$ & $30-40$ \\
$15-22$ & $40-30$ \\
$22-27$ & $30-20$ \\
\hline
\end{tabular}

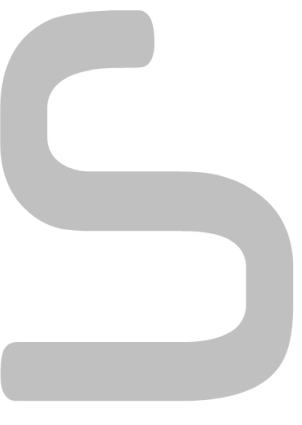

Injected Ixora chinensis Lamk flower extract $10 \mu \mathrm{l}$ to the system and compared with the standardized compound of $1=$ gallic acid, $2=$ catechin, $3=$ chlorogenic acid, $4=$ rutin, $5=$ ferulic acid, $6=$ quercetin at concentrations of $50-500 \mu \mathrm{g} / \mathrm{ml}$ using 280 nanometer wavelength for analysis of active ingredient compounds of total phenolic compounds in Ixora chinensis Lamk flower extract as showed in the table 9.[11]

Table.9 Showed the analysis of active compounds by HPLC method

\begin{tabular}{|l|l|l|l|l|l|}
\hline sample & compounds & replication & $\begin{array}{l}\text { Retention } \\
\text { time }\end{array}$ & $\begin{array}{l}\text { Area } \\
\text { under } \\
\text { curve }\end{array}$ & $\begin{array}{l}\text { Contents } \\
\text { (ug/mg extract) }\end{array}$ \\
\hline \multirow{2}{*}{$\begin{array}{l}\text { Ixora } \\
\text { chinensis } \\
\text { Lamk }\end{array}$} & Gallic acid & 1 & 4.89 & 4957870 & 13.60 \\
\cline { 2 - 6 } & 2 & 4.90 & 4987930 & 13.69 \\
\cline { 2 - 6 } & 3 & 4.87 & 4943170 & 13.56 \\
\cline { 2 - 6 } & mean & 12.74 & 13.62 \\
\cline { 2 - 6 } & sd & 1 & 1286300 & 5.28 \\
\cline { 2 - 6 } & Rutin & 1 & & \\
\hline
\end{tabular}




\begin{tabular}{|l|l|l|l|l|l|}
\hline & 2 & 12.69 & 1517620 & 6.23 \\
\cline { 2 - 5 } & 3 & 12.65 & 1639610 & 6.73 \\
\cline { 2 - 5 } & mean & & 6.08 \\
\cline { 2 - 5 } & sd & 0.74 \\
\hline
\end{tabular}

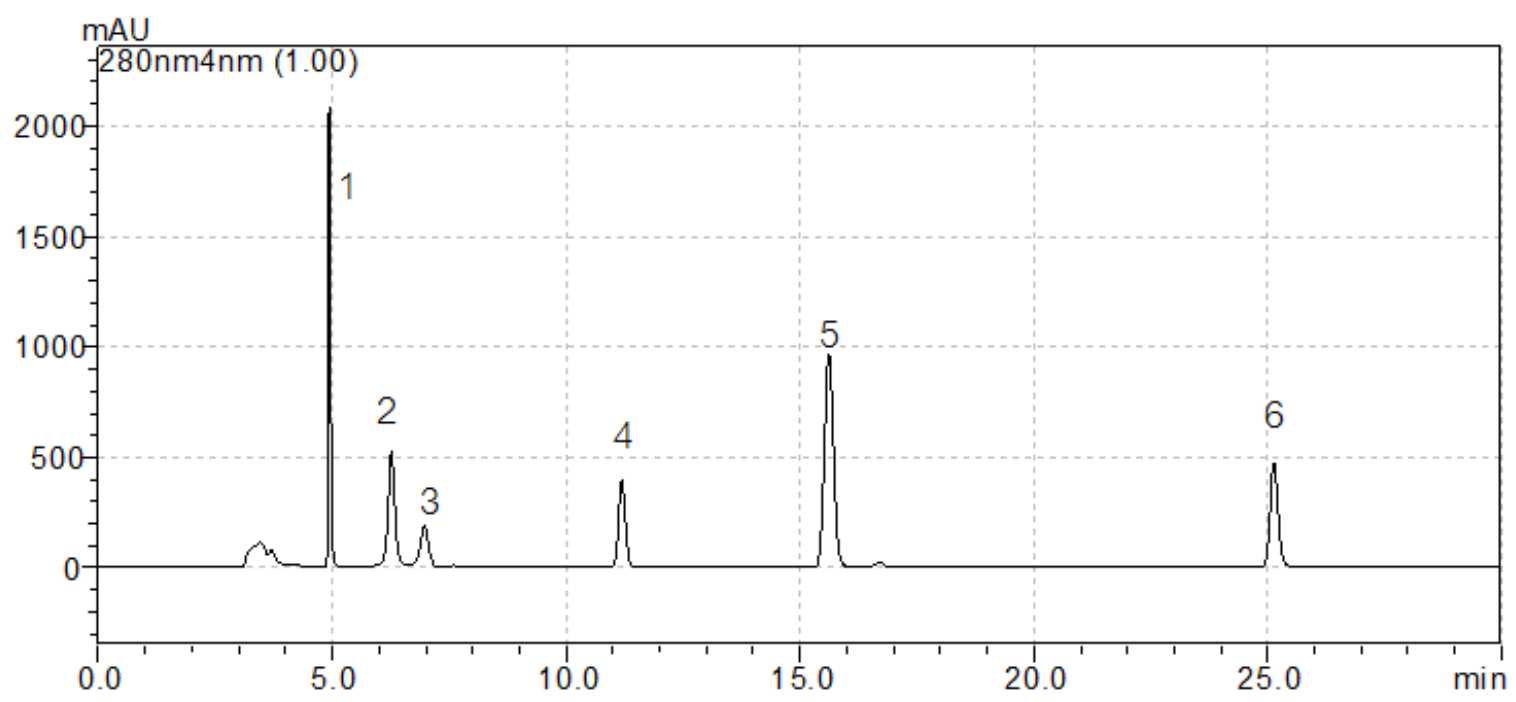

Diagram showed chromatogram of standardized compounds (standard no. $1=$ gallic acid, $2=$ catechin, $3=$ chlorogenic acid, $4=$ rutin, $5=$ ferulic acid, $6=$ quercetin $)$

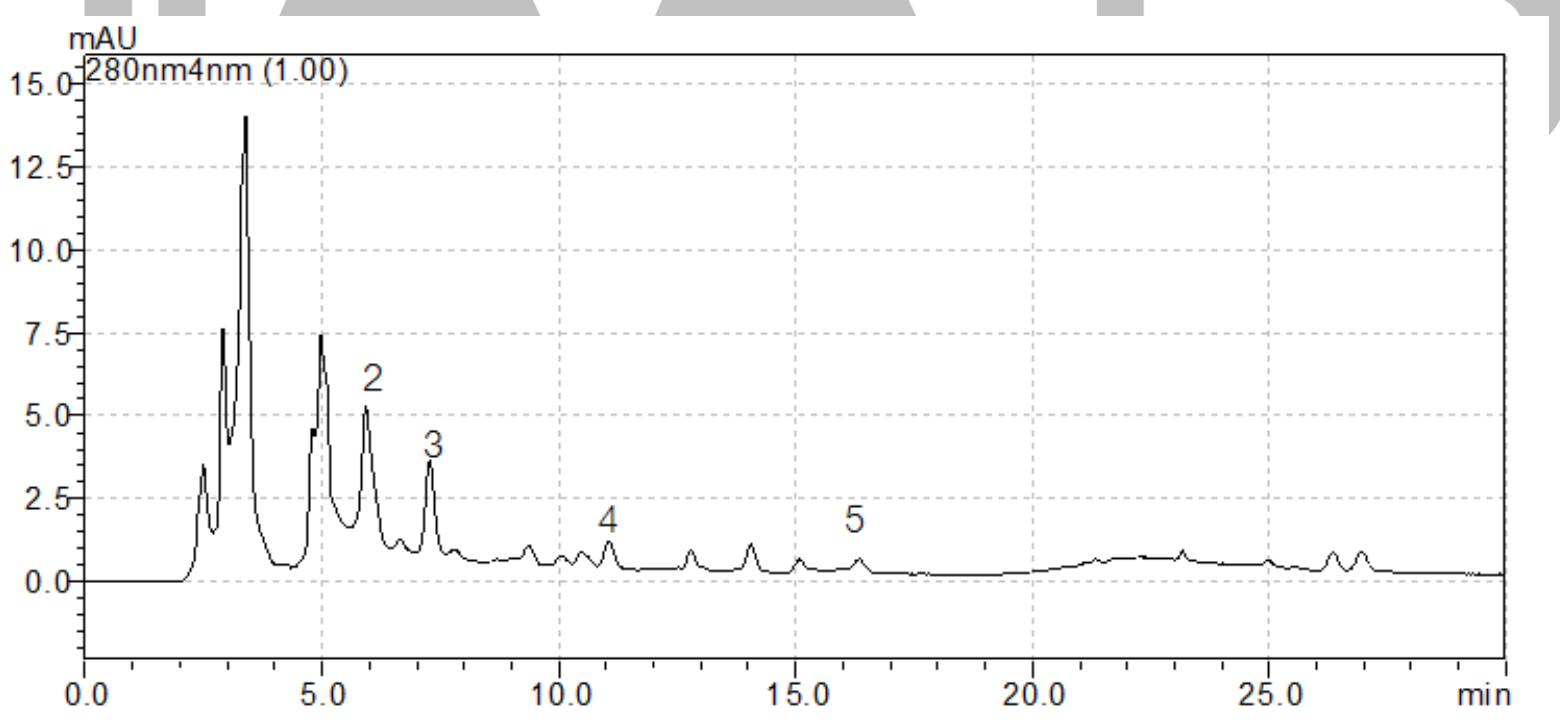

Diagram showed chromatogram of Ixora chinensis Lamk flower extract (1= gallic acid, $2=$ catechin, $3=$ chlorogenic acid, $4=$ rutin, $5=$ ferulic acid, $6=$ quercetin $)(12)$

Discussion : The antioxidant activity analysis by DPPH method was found that there were no statistical significant different ( $\mathrm{p}$-value 0.05 ) between $50 \%$ and $40 \%$ ethanol macerated Ixora chinensis Lamk flowers and standard vitamin $\mathrm{C}$ at day $6^{\text {th }}$ and gave the highest antioxidant activity using macerated $50 \%$ ethanol Ixora chinensis Lamk at day $6^{\text {th }}$ was 
$0.03 \pm 0.00$. The antioxidant activity analysis by ABTS method (IC 50) unit $\mathrm{mg} / \mathrm{ml}$ was found that there were no statistical significant difference ( $\mathrm{p}$-value 0.05 ) between $40 \%$ ethanol macerated Ixora chinensis Lamk flowers and sonicated with $40 \% \mathrm{EtOH}$ and gave the highest antioxidant activity using sonication with $40 \%$ ethanol and showed the result of $0.64 \pm 0.33$. The antioxidant activity analysis by FRAP method (Fe $\mu \mathrm{g} / \mathrm{mg}$ of sample ) was found that there was the highest antioxidant activity with macerated Ixora chinensis Lamk flowers in maceration in $50 \% \mathrm{EtOH}$ at $\mathrm{d} 2^{\text {nd }}$ with the result of $5.40 \pm 0.17$. The result of the highest total phenolic compound in Ixora chinensis Lamk flower extracts ( $\mu \mathrm{g}$ of gallic acid/ $\mathrm{mg}$ of sample) with macerating in $50 \%$ ethanol at $\mathrm{d}_{7^{\text {th }}}$ was $0.30 \pm 0.00$. The result of the highest total flavonoids in Ixora chinensis in 50\% ethanol at $\mathrm{d} 7$ th was $0.39 \pm 0.33$. The result of acute toxicity analysis of Ixora chinensis Lamk flower extracts in wista white rats showed no sign of death or abnormality with no toxicity which could indicate no acute toxicity in Ixora chinensis Lamk flower extracts. The HPLC results from Ixora chinensis Lamk flower extracts showed that mean of Gallic acid and Catechin contents $(\mu \mathrm{g} / \mathrm{mg}$ extract) were 13.62+/- 0.06Mean +/ - SD.) and 6.08 +/- 0.74 (Mean +/- SD.) respectively.

Conclusion: In conclusions, all active ingredients from the flower extract showed no statistical significant difference between macerating with water, $40 \%$ ethanol , $50 \%$ of ethanol and using ultrasonication method which we suggested that using ultrasonication extraction was convenience and could decrease production time for mass production although the cost of equipment was costly. We also would like to confirm that Ixora chinensis Lamk. flower extract health drink was safe after certified by acute toxicity test and also contained high anti oxidant active ingredients. Therefore it would be suitable for developing anti aging health drink for the future. The further market analysis with sensory test should be essential for developing the quality product relating to the customer needs in the further research.

\section{References}

1. Abdelwahab SI (2010) Chemical composition, antioxidant and antibacterial properties of the essential oils of Ixora chinensis Lamk Kochummen. J Science Food Agric. Dec; 2682-8. 2. Akoh, C. C. and Min, B.D (1998) Antioxidants In Food Lipids. Publisher, New York

AOAC.Official method of analysis of AOAC International (2005) AOAC official method Moiture in Malt. Publisher, USA: Maryland

3.Apisariyakul, A., N. Vanittanakorn and D. Buddhasukh (1995) Antifungal activity of turmeric oil extracted from Curcuma longa (Zingiberaceae). J. of Ethnopharmacology:163-9.

4.Chan EW (2011) Standardised herbal extract of chlorogenic acid from leaves of Etlingera elatior (Zingiberaceae).. Pharmacognosy Res. Jul:3.178-84.

5.Eric Chan Wei Chiang (2011) Analysis and Evaluation of Antioxidant Properties of Thai Herbal Teas. International Journal for the advancement of science and arts:8-15.

6.E.W.C. Chan, Y.Y. Lim and Mohammed Omar (2007) Antioxidant and antibacterial activity of leaves of Etlingera species (Zingiberaceae) in Peninsular Malaysia. Food Chemistry: 1586-93

7.Faridahanim Mohd Jaafar (2007) Analysis of Essential oil of Leaves, Stems, Flowers and Rhizomes of Etlingera Elatior (JACK) R. M. Smith. The Malaysian Journal of Analytical Sciences :269-73.

8.Farnworth, N.R. and N. Bunyapraphatsara (1992) Thai Medicinal Plants Recommeded for Primary Health Care System. Prachachon Co., Ltd, Bangkok : Thailand 
9.Habsah Mohamad, Nordin Lajis et al (2005) Antioxidative Constituents of Etlingera elatior. J. Nat. Product :285-88.

10.Pawinee Deetae, Sittiwat Lertsiri et.al (2012) Antioxidant and anti-glycation properties of Thai herbal teas in comparison with conventional teas. Food Chemistry. Aug):953-59.

11. H. Sumathy, J. Sangeetha, K. Vijayalakshmi* Chromatographic Fingerprint Analysis of Ixora coccinea Methanolic Flower Extract ,International Journal of Pharmaceutical Sciences and Drug Research 2011: 327-30

12. Angeline Torey ${ }^{\mathrm{a}}$, Sreenivasan Sasidharan ${ }^{*}$, Lachimanan Yoga Latha ${ }^{\mathrm{c}}$, Sivaramakrishnan Sudhakaran ${ }^{\mathrm{a}}$ \& Surash Ramanathan ${ }^{\mathrm{d}}$, Antioxidant activity and total phenolic content of methanol extracts of Ixora coccinea, Pharmaceutical Biology Volume 48, Issue 10, 2010 , pages 1119-23.

13. Magdy M. D. Mohammed ${ }^{1,2 *}$ and et. al

Rubiothiazepine a Novel Unusual Cytotoxic Alkaloid from Ixora undulata, Natural Products Chemistry \& 2:128

14. LU Luan-mei, LIN Jin-shui, XIE Zhi-ming, Effects of Different Preservative Solution on Cut Flowers of Ixora chinensis, Acta Horticulturae Sinica, Year 2010: 1351-56.

15. T. K. Lim , Flowers, Edible Medicinal and Non Medicinal Plants 1-71.

16. Sivarajan VV, Balachandran I (1941), Ayurvedic Drugs and Their Plant Sources; Oxford and IBH Publishing Co., New Delhi, India.

17. Surana A. R., Aher A. N.2 and Pal S., Vitro and in vivo antioxidant activity of Ixora coccinea, Journal of Medicinal Plants Research :3071-75.

18. Moni Rani Saha, Md. Ashraful Alam, Raushanara Akter and Rumana Jahangir . In vitro free radical scavenging activity of Ixora coccinea L . Bangladesh J Pharmacol 2008: 90-96 .

19. Torey A, Sasidharan S, Latha LY, Sudhakaran S,$\underline{\text { Ramanathan S. }}$,Antioxidant activity and total phenolic content of methanol extracts of Ixora coccinea., Pharm Biology 2010 Oct: 1119-23.

20. Bunleu Sungthong, Chirapha Butiman, Kusuma Jitsaeng. Optimizied Ultrasonication Asissted Extraction ,Antioxidant from Mulberry (Morus alba L.) Leaves using Multiple Linear Regression Analysis. International Journal of Pharmacy and Pharmaceutical Sciences, 2014: 914-17.

21. . Seifried HE, Anderson DE, Fisher EI, Milner JA. A review of the interaction among dietary antioxidants and reactive oxygen species. Journal of Nutritional Biochemistry 2007; $567-57$ 